Supporting Information

\title{
Ion Solvation and Water Structure in an Aqueous Sodium Chloride Solution in the Gigapascal Pressure Range
}

\author{
Toshio Yamaguchi ${ }^{1}{ }^{*}$, Nami Fukuyama ${ }^{1}$, Koji Yoshida $^{1}$, Yoshinori Katayama ${ }^{2}$ \\ ${ }^{1}$ Department of Chemistry, Faculty of Science, Fukuoka University, Jonan, Fukuoka 814-0180, Japan \\ ${ }^{2}$ Synchrotron Radiation Research Center, National Institutes for Quantum and Radiological Science and
}

Technology, Sayo, Hyogo 679-5148, Japan 
Table 1S. Thermodynamic conditions and density of a $3 \mathrm{~m} \mathrm{NaCl}$ aqueous solution measured by X-ray diffraction experiments and EPSR modeling.

\begin{tabular}{cccc}
\hline$T / \mathrm{K}$ & 300 & 300 & 300 \\
$P / \mathrm{GPa}$ & 0.00010 & 1.3 & 1.7 \\
$\rho / \mathrm{g} \mathrm{cm}^{-3}$ & 1.10 & 1.55 & 1.69 \\
\hline
\end{tabular}

Table 2S. The parameter values of the pair potentials employed in the EPSR modeling.

\begin{tabular}{ccccc}
\hline & $\mathrm{O}$ & $\mathrm{H}$ & $\mathrm{Na}$ & $\mathrm{Cl}$ \\
\hline$\varepsilon\left(\mathrm{kJmol}^{-1}\right)$ & 0.65 & 0.00 & 0.54431 & 0.4187 \\
$\sigma(\AA)$ & 3.16 & 0.00 & 2.35 & 4.40 \\
Mass & 16 & 1 & 23 & 35.44 \\
Charge & -0.8476 & 0.4238 & 1.0 & -1.0 \\
\hline
\end{tabular}



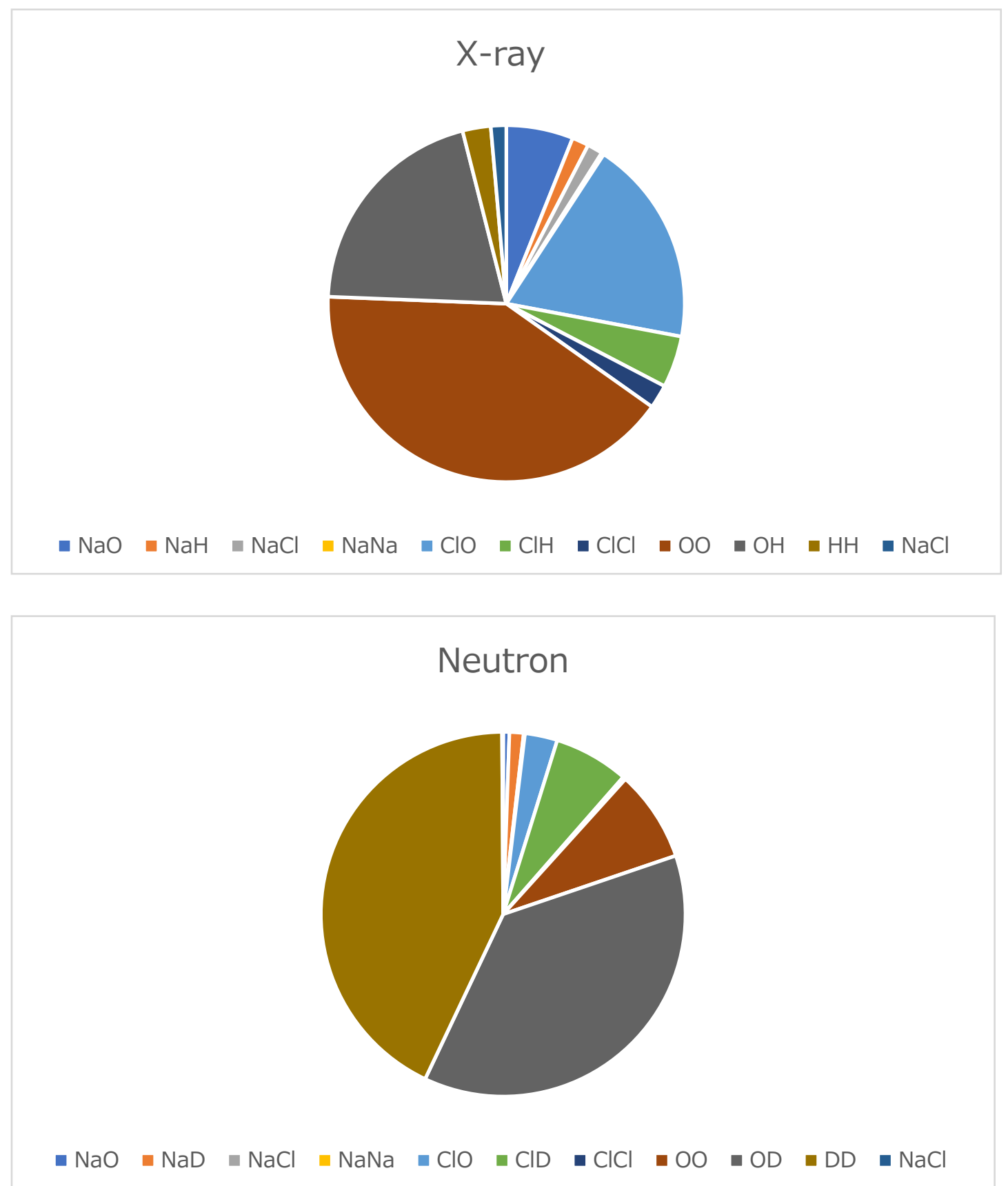

Figure 1S. Comparison of the contribution of the individual atom-pairs to the total scattering for $3 \mathrm{~m} \mathrm{NaCl}-\mathrm{H}_{2} \mathrm{O}$ solution by X-ray and neutron. The dominant contributions for $\mathrm{X}$-rays are $\mathrm{O}-\mathrm{O}, \mathrm{O}-\mathrm{H}, \mathrm{Cl}-\mathrm{O}$, and $\mathrm{Na}-\mathrm{O}$, while those for neutron are $\mathrm{OD}, \mathrm{DD}, \mathrm{OO}$, and $\mathrm{CID}$. In case of neutron diffraction experiments, $\mathrm{D}$ atom is used for hydrogen to avoid the large incoherent scattering of $\mathrm{H}$ atom. 

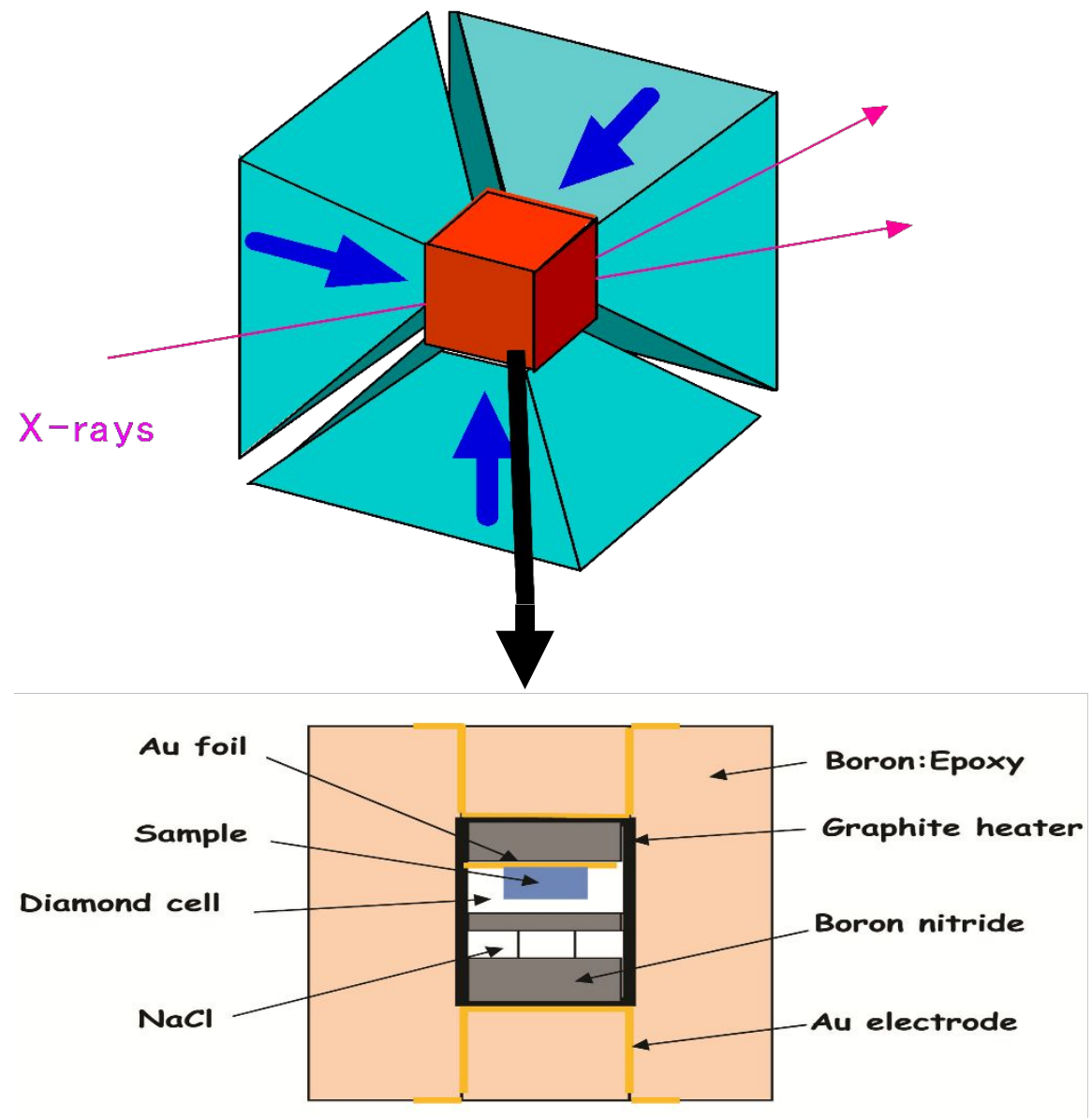

Figure 2S. The cross-section of a high-pressure cell assembly 